monitor showed the sudden onset of sinus tachycardia and right axis deviation. Gastric aspirate at this time showed no blood. Despite the normal aspirate it was considered that he was bleeding again and laparotomy was performed. A duodenal tumour (a benign haemangioma) was found and removed after a long and difficult dissection. The small bowel was full of blood. Recovery was uneventful.

Comment.-The cause of the electrocardiographic change is not obvious, but it may have been due to pulmonary vasoconstriction in the face of a falling blood volume. The close monitoring by the nursing staff enabled us to diagnose further bleeding at a very early stage. He was therefore operated on while his general condition was still good and before a profound acidosis had been induced by multiple transfusions of stored blood. He was thus well able to stand an extensive operative procedure.

\section{Cor Pulmonale with Resistant Oedema}

A female, A.S., aged 43 years, with long-standing chronic bronchitis, was admitted to the general ward in severe congestive cardiac failure. The oedema was resistant to all diuretic therapy and she gradually deteriorated, at the same time becoming drowsy with a raised $\mathrm{PCO}_{2}(150 \mathrm{~mm}$. $\mathrm{Hg})$. She was transferred to the I.T.U. and tracheostomy was performed. Positive pressure ventilation was instituted and continued for one week. The massive oedema resolved completely and the $\mathrm{PcO}_{2}$ fell to $65 \mathrm{~mm}$. $\mathrm{Hg}$ (her average level during the previous two years). She subsequently made a satisfactory recovery and was discharged home.

Comment.-This patient fits into the group of chronic bronchitics known as "blue bloaters" in whom there is a noticeable absence of dyspnoea associated with cyanosis and recurrent congestive cardiac failure. Before admission to the I.T.U. she was thought to be in terminal cardiac failure with total resistance to diuretic therapy. The resolution of the massive oedema and her subsequent recovery with assisted ventilation was impressive. Long-continued controlled ventilation of this type would have been extremely difficult to carry out on a general ward.

\section{Conclusions}

There are several reasons why intensive therapy units of this type should be considered by others-the more economic use of trained nursing staff, in increasingly short supply; the needless expenditure in duplicating very expensive equipment throughout the hospital ; and the building up of a team trained in the use of complicated monitoring and therapeutic equipment.

It is our experience that one intensive care bed is required for every hundred acute beds. Thus if the district hospitals of the future are large enough to carry all necessary services, they will need possibly 1,000 beds and a 10-bedded I.T.U. Assuming an average stay of three days, which has been our experience, this unit could admit approximately 1,000 patients a year. It would of course have to carry a permanent staff and we would suggest at least three registrars, one of whom would do night duty every third week and be relieved of day duties. The setting up of such units would be expensive in both manpower and money, but we believe that they will prove indispensable in future hospital services.

We would like to thank the Matron of the Royal Southern Hospital, Miss A. M. W. White, and also Sisters J. Owen and A. Percival and their nursing staff; Dr. C. M. Ogilvie, Dr. C. A. St. Hill, and Dr. J. E. Riding, the consultants in charge of the unit, for their advice and criticism of this paper; and the staffs of the intensive care units at Whiston and Broadgreen Hospitals for advice in the early stages of the unit. Dr. R. W. Brookfield, Dr. E. Sherwood Jones, and Dr. J. T. Robinson also advised in the planning of the unit. We would also like to thank the United Liverpool Hospitals for generous financial support.

\section{REFBRENCE}

Cam, J. F., Grogono, A. W., and Lee, H. A., Lancet, 1964, 2, 1168.

\title{
Advisory Service for Parents of Mentally Handicapped Children*
}

\author{
BRIAN H. KIRMAN, $\dagger$ M.D., D.P.M.
}

Brit. med. F., 1966, 1,41-44

There has been a reversal of attitude in regard to mental handicap. Previously institutional care was recommended and was looked upon as almost inevitable. The emphasis now is on integration into the community rather than on segregation in special colonies or hospitals. It should only be necessary to provide residential care in those cases where the parent is unable to cope. The great majority of the mentally retarded in the feeble-minded or subnormal range should, in any event, be included within the educational system and should go on to independent employment.

It should, however, be frankly recognized that the care of severely mentally handicapped children does place a heavy additional burden upon parents. The problems of such families have been set out by Tizard and Grad (1961). They have also been expressed by parents themselves through their organizations such as the National Society for Mentally Handicapped Children (formerly the National Association of Parents of Backward Children), and in the United States by the National Association for Retarded Children.

\footnotetext{
* Paper read at a meeting of the Paediatric Section of the Royal Society of Medicine at Queen Mary's Hospital for Children, Carshalton, on 29 May 1965.

t Consultant Psychiatrist, Fountain and Carshalton Hospital Group.
}

Some of the difficulties which the parents of a backward child have to face may be material; some are psychological; in others there is a combination of adverse circumstances in which the handicapped child occupies a central position. One mother who came for advice has a malformed, crippled, mentally retarded child. During her pregnancy she had a loss of blood, which was thought to be aetiologically related to the abnormality in the child. She is now pregnant again. She has again had a loss of blood. She has been advised to rest, but the care of her handicapped child involves carrying it up 60 steps to her home. This is an example of an obvious physical difficulty. In other cases with professional parents it may be difficult for them to reconcile themselves to the fact that their child is intellectually limited, and they may reject him. A mother with a child of low imbecile level may find that each step in development takes him some five times as long as the normal child. She will be washing napkins for a very long time, and may despair of progress.

Parents of backward children need help in two ways. First, they need material help in the way of training centres, day nursery accommodation, rehousing, and, in some cases, financial assistance. Secondly, they need advice and understanding. To some extent this can be provided by the organ- 
ized efforts of local parents and through other voluntary channels, but it is becoming increasingly obvious that what is needed is expert guidance at an early stage. Existing local authority child guidance and infant welfare clinics and hospital psychiatric and paediatric out-patients may have only a limited interest in or experience of the needs of the mentally retarded. For this reason it seems desirable, first, that special clinics for advising the parents of retarded children should be set up, and, secondly, that other children's clinics should be in a position to provide such advice.

\section{Clinics for Retarded Children}

A number of such special clinics have been organized by paediatricians, psychiatrists, and by local authorities who have shown a particular interest in the subject. Existing clinics do not satisfy the demand, and it seems in the present experimental stage that efforts from all these three and other directions should be welcomed. The composition of the team providing advice is perhaps more important than the auspices under which the clinic is organized. The best formula may be that it should be available as part of the hospital service, but closely linked with the local authorities and possibly the result of joint effort.

The advisory service which was instituted at the Fountain Hospital after the second world war and which has since continued at Queen Mary's Hospital for Children, Carshalton, provides for some 10 children weekly. The clinic is not confined rigidly to the. severely mentally retarded, and a number of other problems in child psychiatry are considered, but these are not included in the number mentioned. Cases are often referred where there is some doubt as to normality-for example, for investigation before adoption. Children are seen who are the subject of an appeal against exclusion from school as ineducable and also children who present educational problems. The numbers seen are kept small so that intensive investigation can be carried out in each case, one of the objects being to provide a service which, while strictly practical, can serve for training and for extension of knowledge about the problems in this field.

\section{Composition of Team}

The clinics are staffed by a consultant psychiatrist or assistant psychiatrist, junior medical staff, psychologist, and social worker. A speech therapist also frequently participates. Otological and neurological clinics are located in the same hospital. Laboratory services which are frequently drawn upon are the biochemical and cytogenetic departments. As a result of a long period of working together with out-patients and with in-patients a highly integrated team has been developed. The neuropathologist, biochemist, members of the teaching staff, the speech therapists, and others participate regularly in case conferences, discussions, in the programme of teaching and research, as well as the psychiatrists, psychologists, and social workers. This facilitates a multi-disciplinary approach to the problem. There is also constant exchange of knowledge and skill between members of different disciplines.

\section{Source of Referral}

As the availability of the service becomes known the number of cases increases and there is in particular a tendency for general practitioners to refer children direct in contrast with the previous position where work with the mentally subnormal was often looked upon as primarily the province of the local authority. Since the new Mental Health Act was introduced in 1960 arrangements have become more informal. Parents, voluntary organizations, teachers, and others are not discouraged from referring patients direct, but wherever possible the general practitioner is informed beforehand and a report is sent to him with any necessary copies to the school medical officer, medical officer of health, referring consultant, or otherwise as indicated. The source of a series of 100 referrals to one consultant is shown in Table I.

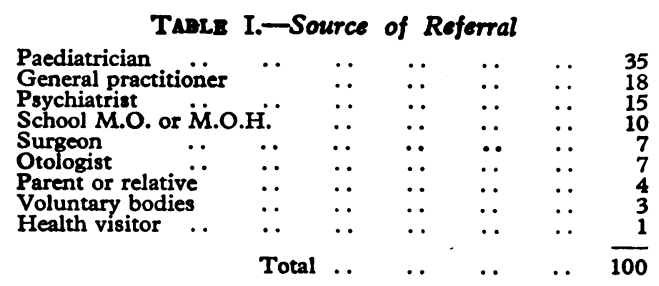

\section{Reason for Referral}

Parents' difficulties with backward children vary very much according to age. The age distribution of 100 referrals is shown in Table II. In young babies there may be a physically recognizable syndrome such as Down's syndrome. Somewhat surprisingly even this well-known condition is not always recognized at birth, but the parents themselves may realize that the child is abnormal and seek advice. In another group of cases the condition has been established but the parents wish for a second opinion; they may be unable emotionally to accept the diagnosis, or they wish for much more detailed information and advice than they have had. In other cases it is a question of a young baby "at risk" after perinatal injury, jaundice, maternal rubella, or other hazard. Where children have an established motor lesion or infantile convulsions or spasms the question of concomitant limitation of intellectual capacity may be raised.

\begin{tabular}{c|c|c|c|c|c|c|c|c|c}
\hline TABLE II. Age and Sex \\
\hline Years: & $0-6 / 12$ & $6 / 12-1$ & $1-2$ & $2-5$ & $5-10$ & $10-15$ & $15-20$ & $20+$ & Total \\
\hline M & 0 & 1 & 3 & 19 & 23 & 9 & 3 & 1 & 59 \\
F & 0 & 0 & 2 & 11 & 14 & 9 & 4 & 1 & 41 \\
\hline Total & 0 & 1 & 5 & 30 & 37 & 18 & 7 & 2 & 100 \\
\hline
\end{tabular}

TABLB III.-Reason for Referral

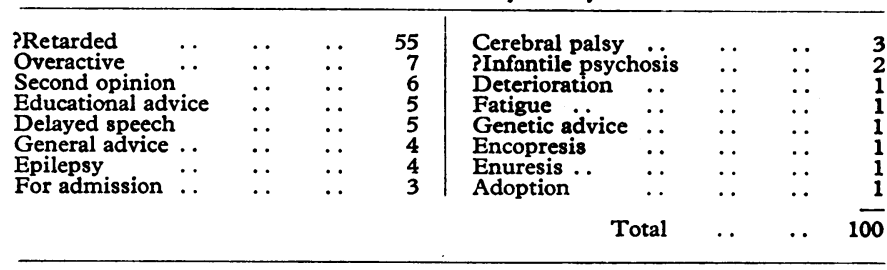

The time of most acute stress for parents in the group above comes soon after the birth of the child. In other cases mother and baby are discharged from hospital, the infant is reported in a satisfactory condition but fails to make progress. The parents or grandparents, however, gradually realize that all is not well. They often report that their doubts are dismissed with hearty reassurance, but eventually specialist advice is sought, perhaps because at 1 year the child is still not attempting to sit or does not respond to speech and is thought to be deaf.

A third and usually less severely retarded group of children are referred when they are at or approaching the age of attending school. At 5 years a child may still be incontinent of urine, have limited speech, or be insufficiently biddable in class to conform to group discipline, though previously accepted as normal in the home. A fourth group is made up of teenagers of feebleminded level of intelligence showing behaviour disorders, usually associated with unfavourable domestic and social circumstances. Table III shows the chief reason for referral of 100 cases. 


\section{Assessment and Diagnosis}

In a majority of cases no clinical diagnosis can be made, though with the severely subnormal a gross encephalopathy can be assumed. This is also the cause of the secondary disabilities of epilepsy and cerebral palsy when these are present. Table IV shows the main diagnosis of 100 cases, and Table V shows numbers with major secondary handicaps. Though precise diagnosis is important for genetic advice and occasionally for treatment, also ultimately for prevention, the parents are more likely to be immediately interested in prognosis in regard to schooling and eventual employment, or in severe cases in regard to iife. Such an assessment calls for careful, standardized, and often repeated psychological examination coupled with due consideration to the social history and the clinical findings. A long-term prognosis in a very young infant is always hazardous and is usually based on something other than behaviour, since the repertory of the baby under 3 months is limited. For example, in Down's syndrome it is of ten difficult to demonstrate any developmental deviation from the norm at 3 or 6 months, though retardation becomes apparent at a later stage. Certain generalizations may be permitted which are useful guidance for parents. In Down's syndrome the average expectation is that the child will do as well intellectually as his peer of about one-third the age. In other words, he will stay a baby three times as long. He will seldom succeed in competitive employment. If the head circumference of a young child is more than three standard deviations below the mean for age and sex it will probably be seriously retarded. If the placing reactions are absent in a baby of normal birth weight this may suggest a degree of abnormality of the brain incompatible with normal mental development (Zappella, 1963, 1964 ; Zappella et al., 1964). In phenylketonuria and cretinism much will depend on the age at diagnosis. A summary of intellectual assessment of 100 patients is shown in Table VI.

TABLE IV.-Main Diagnosis

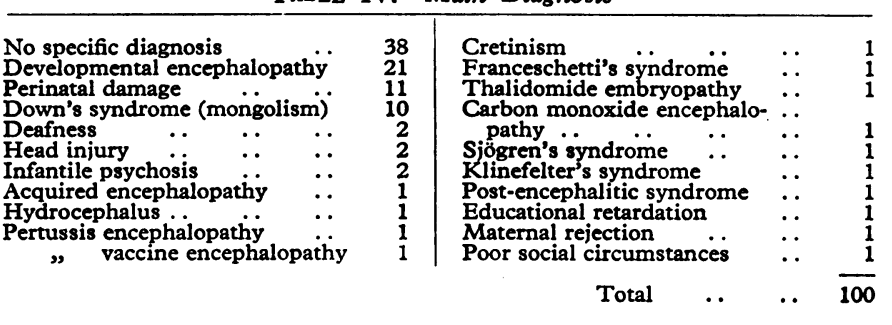

TABLE V.-Major Secondary Handicap

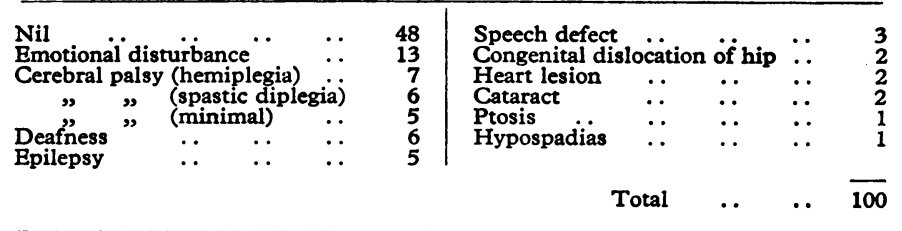

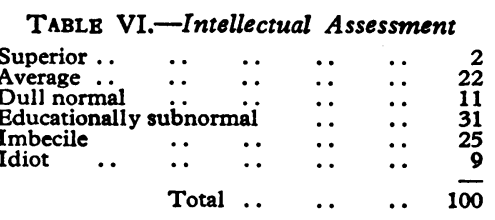

\section{Recommendation}

An interview with parents of backward children and with the child has a therapeutic quality and purpose. Our procedure involves a series of interviews and subsequent group discussion with the psychiatrist, psychologist, and social worker, possibly with other members of the staff. Wherever possible the father is seen as well as the mother. Sometimes other relatives, grandparents, siblings, take part. Formal recommendations emerging from interview do not always reflect the exchanges which took place or alteration of attitude which may have occurred. The social worker carries out a home visit before the clinic appointment. This also has a therapeutic role, and practical suggestions may be made at the same time in regard to clothing, bedding, use of sleeping accommodation, housing, independence, visits to shops, local contacts, and membership of a local branch of the National Society for Mentally Handicapped Children, etc. Major recommendations are shown in Table VII.

TABLB VII.-Main Recommendations

\begin{tabular}{|c|c|c|c|c|c|}
\hline \multirow{3}{*}{$\begin{array}{l}\text { Waiting-list for institutional care } \\
\text { Admit to unit for disturbed } \\
\text { children } \\
\text { Admit to paediatric unit } \quad . .\end{array}$} & \multirow[t]{4}{*}{5} & \multirow{4}{*}{$\begin{array}{l}\text { Suitable employment } \\
\text { More stimulation } \\
\text { Reassurance } \\
\text { Speech therapy }\end{array}$} & \multirow{2}{*}{$\because$} & \multirow{2}{*}{$\because$} & \multirow{4}{*}{$\begin{array}{l}3 \\
1 \\
4 \\
2 \\
1\end{array}$} \\
\hline & & & & & \\
\hline & & & $\cdots$ & - & \\
\hline $\begin{array}{lll}\text { Residential unit } & \ldots & \ldots\end{array}$ & & & $\ddot{\cdots}$ & $\because$ & \\
\hline " nursery. & 3 & Hearing aid $\quad$. & . & .. & 1 \\
\hline $\begin{array}{l}\text { Day nursery } \\
\text { Nursery school }\end{array} \cdots \quad \cdots$ & 3 & Special chair $\ldots$ & $\cdots$ & $\cdots$ & 1 \\
\hline $\begin{array}{l}\text { Nursery school (deaf) } \\
\end{array}$ & 1 & Enuresis alarm... & $\ddot{\circ}$ & $\because$ & \\
\hline $\begin{array}{lll}\text { Ordinary school } & \ldots & \ldots \\
\text { Remedial class } & & \end{array}$ & 1 & Lodgings $\quad \because \bar{c}$ & $\because$ & $\because$ & 1 \\
\hline School for educationally sub- & & Patient to join children & & & \\
\hline $\begin{array}{ccc}\text { normal (day) } & \ldots & \ldots\end{array}$ & 9 & organization.. & .. & . & 3 \\
\hline $\begin{array}{l}\text { Ditto (residential) } \\
\text { School for physically handicapoed }\end{array}$ & 3 & Adoption & . & $\cdots$ & 1 \\
\hline School for the deaf & $\frac{1}{2}$ & Parents to join Nation & iis & ety & \\
\hline Open air school $\quad \ldots$ & 1 & for Mentally Han & adic & & \\
\hline Training centre (day). & & Children $\quad .$. & .. & .. & \\
\hline care unit (day) & & Rehousing & . & . & \\
\hline ther assessment $\quad$. & 3 & Nil specific & . & .. & 1 \\
\hline & & Total & .. & . & 100 \\
\hline
\end{tabular}

\section{Objectives}

It is possible to make some generalizations as to the role of such a service. Acceptance and integration in the community can be promoted by means of parent guidance. Parents may believe that they are wrong in wishing to keep a retarded child at home, and that he would do better in a specialized institution. In fact, institutions are overcrowded; there is a shortage of beds. The waiting-list in this hospital is 120 , mainly young children. This may imply a three-year wait. Furthermore, all the evidence suggests that children do better at home, provided the family is able to carry the burden.

Other parents reject a child at an early stage. They may have been influenced by an unsympathetic or brusque attitude on the part of those around them. It is important that parents should be able to discuss their problems in relation to a retarded child at some length, and that they should have patient and sympathetic hearing. A helpful, informed, and interested approach will encourage a positive response in the parent. Often the mother or father is anxious for information, and may underestimate the developmental potential of a handicapped child or may be worried about whether to have further children. A special clinic such as I have described is in a position to supply information and to elicit parental difficulties and anxieties.

\section{Summary}

The emphasis is now on community care of the mentally handicapped. Institutions should be used only as a last resort. But the family with a mentally handicapped member is carrying an additional burden. In some cases material help is needed. In all cases advice should be available. Special clinics for the mentally handicapped are very valuable. One such clinic is described. A team of workers is needed who are in sympathy with and have experience of the needs of parents of mentally handicapped children. The team at Queen Mary's Hospital for Children comprises psychiatrists, junior medical staff, psychologists, psychiatric social workers, and speech therapists. Other specialist services are available. Children are most frequently referred by paediatricians on account of suspected 
mental retardation. In $38 \%$ no specific diagnosis was made, $52 \%$ have a secondary handicap. Thirty-one per cent. of outpatients are in the educationally subnormal range and $34 \%$ severely subnormal. The commonest specific recommendations were for attendance at day nursery or nursery school, day training centre or special care unit.

\section{REFERENCES}

Tizard, J., and Grad, J. C. (1961). The Mentally Handicapped and Their Families. Maudsley Monograph, London. Zappella, M. (1963). Develop. med. Child Neurol., 5, 497. (1964). Proceedings of the International Copenhagen Congress on the Scientific Study of Mental Retardation, p. 474. - Foley, J., and Cookson, M. (1964). F. ment. Defic. Res., 8, 1.

\section{Medical Education Overseas}

\section{[From a Special Correspondent]}

The Medical and Technical Education Study Group of the International Co-operation Year held a symposium on "Methods of Teaching Large Numbers of Medical Personnel in Developing Countries" at the Ciba Foundation on 30 November, under the co-chairmanship of Dr. J. R. Ellis (London Hospital) and Professor K. R. Hill (Royal Free Hospital).

The symposium was opened by Sir ArTHUR PorritT, who gave an account of the recent Commonwealth Medical Conference at Edinburgh. He outlined the proposed establishment of supernumerary appointments in this country, at both university and regional hospitals, to enable doctors to visit developing countries more easily on secondment, and stressed the importance of the general duty officer who was trained in environmental, preventive, and social medicine. Many developing countries rejected the concept of the " medical assistant," and demanded fully trained doctors.

Dr. S. Gauvain (London) discussed the results of a small survey carried out with postgraduate students on the relative merits of the didactic lecture and the seminar. The former had been found to be the more popular with students, but there seemed to be little difference in the examination results achieved by either method.

\section{Role of Textbooks}

Mr. J. A. Rivers (London) emphasized the importance of textbooks as an instrument of individual study. The subject matter of the textbook was the responsibility of the medical and allied professions, who should take into account the geographical pattern of disease when designing new books. He felt that. English was the best medium for instruction, but believed that authorship by indigenous doctors was desirable. Unfortunately, textbooks published for local use had a restricted market and tended to be uneconomic. This drawback might be overcome by introducing cheaper methods of printing and obtaining subsidies from outside Governments and agencies.

Dr. Valerie Graves (Chelmsford) described the advantages of teaching by magnetic tape, but stressed that the subject matter needed careful selection. Tapes were great savers of time and labour, in that one recording could be used over and over again by many students, and they could also be sent to remote centres which were inaccessible to teachers. They were particularly useful in continuing education, especially if combined with slides, film, or filmstrips.

In the discussions following these two papers, opinions were expressed that the standard textbook was out-dated, and that shorter, instructional manuals should replace them ; reduction of "the vocabulary load" was advocated, so as to make the content more easily understandable in developing countries, in which English was not the first language.

\section{Use of Films}

Professor J. K. Russell (Newcastle) discussed the advantages of films as an adjunct to other methods of teaching. He recommended the use of silent films of short duration, accompanied by a commentary by an experienced teacher. Films could show many aspects which could not be explained verbally, but the preparation needed to be scrupulous and the co-operation of a professional photographer was a necessity.

Long films were deprecated in subsequent discussions, but loop films, which lasted a very short time and could be used over and over again, were recommended. Lantern slides or short films, accompanied by a commentary in English on a half-track magnetic tape, were suggested; these could be added to by a commentator speaking in the local language on the other half-track. It was generally agreed that magnetic tapes and films tended to get out of date, and that they should be periodically revised or discarded.

\section{Programmed Teaching}

Dr. Griffiths Owen (Newcastle) discussed the use of programmed teaching. $\mathrm{He}$ reported that at Newcastle such teaching (using machines) had produced an overall result as good as that by lecturers in the field of electrocardiography. He emphasized that programmed teaching demanded active participation by the student. Recent work had suggested that scrambled textbooks were as efficacious as machines. If this were so, they might be found to be the most economic and practicable method for developing countries.

\section{Closed-circuit Television}

Mr. C. E. ENGri (London) described the successful use of closed-circuit television in teaching large numbers of students. This was particularly useful in allowing image magnification-e.g., of an anatomy dissectionand permitted much saving of the teacher's time. As learning in medicine depended considerably on visual experience, the television camera was a useful adjunct to the usual form of instruction, especially when used for unobtrusive observation-e.g., in operating theatres and psychiatric clinics.
Dr. S. Cameron (London) said that opencircuit television for medical education was as yet in its infancy, and that the use of sound radio allied to visual material such as booklets or slides should not be neglected. Television had a part to play, but it must be realized that it was expensive and needed much technical equipment and organization. Although the general opinion of the meeting agreed with this, it was pointed out that closedcircuit television was now relatively cheap and easy to use ; this was illustrated by Dr. G. B. D. Scotr, who described its use in the teaching of morbid anatomy at the Royal Free Hospital for the past four years. Experience in the United States had shown that large numbers of students could be efficiently taught in this way, despite shortage of teaching staff.

The advantages of videotape were stressed, not only as a method of record but also as a teaching medium which could be used repeatedly or put on film.

\section{Types of Student}

Professor G. MacDonald (London) pointed out that medical training in the developing countries affected two classes of student. The first comprised the great majority who had a relatively low standard of education; in the second were the few who were at universities. In the first group were nurses, laboratory technicians, and auxiliaries of all types, and it should be recognized that they needed an accelerated form of training, which involved the teaching of techniques. This could be done by means of short films and magnetic tapes, provided such methods of instruction inculcated the need to maintain a high standard of work. With the bettereducated students the more elaborate forms of visual aid, such as television, might be used to help to combat the teacher shortage, but it should not be forgotten that the maintenance of elaborate equipment might pose difficulties in some developing countries.

In the general discussion there was agreement that a Teaching Services Centre should be established in the United Kingdom (and also perhaps others in the developing countries). The centre should have several functions: (1) to find out what was wanted in the way of audio-visual aids; (2) to catalogue and locate material which could be used for teaching; and (3) to evaluate material. Consultations with the developing countries would be necessary. Such centres would not necessarily produce audio-visual aids, but rather act as co-ordinators and advisers to universities and other institutions, who would do the programming. 